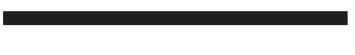

AUTORES:

Adilson Rocha Ferreira ${ }^{1}$

Leonéa Vitoria Santiago

${ }^{1}$ Grupo de Estudos, Pesquisa e

Extensão em Esportes (GEPEXE),

Universidade Federal de Alagoas, Brasi

\section{Os sentidos atribuídos \\ ao Master Handebol \\ em Alagoas}

\section{PALAVRAS CHAVE:}

Esporte. Master Handebol.

Representações sociais. Terceira idade.

\title{
RESUMO
}

O ser humano sempre se preocupou com o processo de envelhecimento, cada um ao seu modo, constituindo assim uma dimensão heterogênea. Cabe salientar o significante papel das representações sociais ao longo do tempo, onde são entendidas como uma categoria de pensamento, resultante de construções simbólicas, funcionando como referencial para a sistematização dos tempos individuais e para a determinação dos ritmos coletivos. Os resultados do estudo indicaram que o Master Handebol contribui significativamente no reencontro de ex-atletas e amantes da modalidade, rememorando o esporte, pois, segundo os discursos dos sujeitos, os festivais são representados como oportunidades que, sem os eventos, os sujeitos não teriam como se reencontrarem e relembrarem seus passados esportivos. Contudo, é notável a necessidade de uma melhor sistematização pertinente à periodicidade em que os eventos ocorrem.

The meanings attributed to the

Master Handball in Alagoas

\section{ABSTRACT}

The human has always worried with the aging process, each in his own way, thus constituting a heterogeneous dimension. It is worth highlighting the significant role of social representations over time, which are understood as a thought category resulting from symbolic constructions, functioning as a benchmark for the systematization of the individual times and for determining the collective rhythms. The study results indicated that the Master Handball contributes significantly in the reunion of former athletes and sport lovers, recalling the sport, because, according to subjects' speech, the festivals are represented as opportunities which without events, the subjects would not have as rediscover and re-member their sporting past. However, it is remarkable need for better systematizing relevant to the frequency at which events occur.

\section{KEY WORDS:}

Sport. Handball master. Social representations. Seniors. 


\section{INTRODUÇÃo}

O ser humano, como um todo, sempre se preocupou com o processo de envelhecimento, cada um ao seu modo, constituindo assim uma dimensão heterogênea. Alguns o caracterizam pela diminuição da capacidade de execução das atividades diárias. Outros, pelo período de crescente vulnerabilidade. Outros, ainda, veneram a velhice como ponto mais alto da vida, devido ao longo tempo percorrido ao longo dela, acumulando sabedoria, bom senso e serenidade ${ }^{(2)}$

Mais de quarenta anos depois da publicação de Serge Moscovici, La psychanalyse, son image et son public (1961), a teoria das representações sociais tem mostrado seu importante papel devido à complexidade dos fenômenos sociais presentes, pois se apoia no conhecimento do senso comum, dos sentidos atribuídos.

É válido salientar o significante papel das representações sociais ao longo do tempo, onde Santigo ${ }^{(9)}$ nos diz que a representação social da temporalidade, é entendida como uma categoria de pensamento, resultante de construções simbólicas, funcionando como referencial para a sistematização dos tempos individuais e para a determinação dos ritmos coletivos.

Com a proposta de formular uma intervenção com caráter recreativo e participativo para ex-atletas de handebol, surge o Master Handebol, modalidade genuinamente alagoana que tem como ideal oportunizar a prática do handebol a ex-atletas com idades superiores a 30 anos, de forma lúdica, não-competitiva, contrapondo-se ao sentimento competitivo presente nas competições de alto nível ${ }^{(1)}$.

Assim, partimos destes pressupostos para elaborarmos os procedimentos metodológicos com o objetivo de analisar e interpretar os sentidos atribuídos pelos sujeitos à prática do Master Handebol, onde a pergunta de partida foi: - 0 que o Master Handebol representa em sua vida?

Visando apresentar as motivações desse estudo, procuramos refletir sobre o Master Handebol, modalidade adaptada à terceira idade, e acreditamos que de algum modo, os conhecimentos adquiridos por meio desse estudo, podem ser generalizados dentro do contexto do esporte para idosos. Percebemos, então, que esses aprendizados, além de apresentarem características individuais, também podem ser considerados como coletivos.

0 estudo se justificou pela necessidade em entender quais os sentidos atribuídos pelos sujeitos ao Master Handebol, com a finalidade de apresentar novas perspectivas do esporte para terceira idade.

As reflexões geradoras deste estudo, de forma inédita espelham-se numa prática de pesquisa do Grupo de Estudos, Pesquisa e Extensão em Esportes - GEPEXE, da Universidade Federal de Alagoas - UFAL.

\section{A TEORIA DAS REPRESENTAÇõES SOCIAIS}

Mais de quarenta anos depois da publicação de Serge Moscovici, La psychanalyse, son image et son public (1961), a teoria das representações sociais tem mostrado seu importante papel devido à complexidade dos fenômenos sociais presentes. Ela tem assumido grande destaque na compreensão dos mais variados objetos e consequente produção do conhecimento.

Uma das preocupações de Moscovici foi a de não fechar um conceito acerca de representação social, recusando-se mesmo a elaborá-lo. Contudo, Jodelet apud Guareschi ${ }^{(3, \mathrm{p}}$ 16), arrisca-se a fazer o que Moscovici não fez à princípio, e considera as representações sociais como "uma forma de conhecimento elaborada e partilhada socialmente, tendo uma visão prática e concorrendo à construção de uma realidade comum a um conjunto social".

Contudo, Sá ${ }^{(8)}$ nos indica que para gerar representação social o objeto deve ter suficiente "relevância cultural" ou "espessura social". Com isso, não faz sentido estudar a representação social de um objeto se esse fenômeno não existe ou não está presente entre os sujeitos, ou seja, se o grupo que escolhemos estudar não tem uma representação do objeto que queremos conhecer, que não está em circulação entre eles.

Representar implica sempre em um sujeito e um objeto, onde o ser pensante - sujeito representa acerca do que vê - objeto - ou seja, representar é a construção do sujeito sobre o objeto, a partir de informações que ele recebe de e sobre o objeto, e não a sua reprodução ${ }^{(8)}$

No que se refere à produção das representações sociais, Moscovici apud Santos ${ }^{(10)}$ sugere dois processos como sendo fundamentais: objetivação e ancoragem.

A objetivação é o processo através do qual o que era desconhecido torna-se familiar. Ele torna concreto o que é abstrato. Transforma um conceito em uma imagem ou núcleo. Segundo Moscovici (4, p.71).

a objetivação une a ideia de não-familiaridade com a de realidade, torna-se a verdadeira essência da realidade. Percebida primeiramente como um universo puramente intelectual e remoto, a objetivação aparece, então diante de nossos olhos, física e acessível.

A ancoragem caracteriza-se pela inserção em pensamento já existente, estabelecendo relações de significações em torno do mesmo. É um processo que torna o desconhecido em conhecido através da comparação de categorias já conhecidas, reajustado para que se enquadre numa categoria previamente estabelecida. Para Moscovici (4, p. 61), "ancorar é classificar e dar nome a alguma coisa".

Desta forma, para que este "desconhecido" se torne conhecido é necessário que se processe uma transformação. Tal transformação é realizada pelo grupo, ao vincular imagens concretas e compreensíveis do seu dia a dia aos novos esquemas conceituais que surgem. 
Belo Horizonte - MG, foram encontrados caminhos que trilhavam para a resolução do problema da continuidade no handebol após a vida adulta. Tais caminhos foram discutidos e

a) Elas 'convencionalizam' os objetos, pessoas ou acontecimentos que encontram. Elas the dão uma forma definitiva, as localizam em uma categoria e as põe como modelo partilhado por um grupo de pessoas;

b) Representações são 'prescritivas', isto é, elas se impõem sobre nós com uma forma imensa, devido a estrutura formada antes que comecemos a pensar e por uma tradição que prediz o que deve ser pensado.

Com isso, que a teoria das Representações Sociais permite a justificativa das tomadas de posição e dos comportamentos dos sujeitos, assim como a manutenção ou reforço dos comportamentos de diferenciação social assumidos pelos grupos sociais ou pelos indivíduos.

\section{O MASTER HANDEBOL: UMA MANIFESTACÃO}

\section{DO HANDEBOL TRADICIONAL}

0 envelhecimento é algo que não se tem como evitar, pois é um processo natural que faz parte do ciclo da vida de todos os seres humanos. Segundo Murray e Lopes ${ }^{(5)}$, o envelhecimento é um processo progressivo e inevitável, caracterizado pela diminuição das funções fisiológicas e de todas as capacidades físicas. Decorrente disso, a prática de exercício físico tem sua peculiaridade para esse grupo, pois necessita de uma sistematização diferenciada, devido às demandas física e fisiológica.

Powers e Howley ${ }^{(6)}$ dizem que grande parte do desempenho em atletas decai constantemente durante a meia idade e a velhice, decorrente da diminuição das resistências muscular e cardiovascular.

No entanto, com a proposta de formular uma intervenção, com caráter recreativo e participativo, para ex-atletas de handebol, surge o Master Handebol, modalidade genuinamente alagoana, implantada em 18 de dezembro de 2004, através do I Festival Master de Handebol, na cidade de Maceió - AL. O Master Handebol tem como ideal oportunizar a prática do handebol a ex-atletas com idades superiores a 30 anos no gênero feminino, e 35 no masculino, de forma lúdica, não-competitiva, contrapondo-se ao sentimento competitivo presente nas competições de alto nível ${ }^{(1)}$.

A modalidade foi idealizada pelo professor Francisco de Assis Farias, em 2004, em suas aulas no Curso de Educação Física, da Universidade Federal de Alagoas - UFAL, na disciplina Metodologia do Handebol, junto com seus alunos matriculados àquela época.

A partir de uma apresentação acerca do Handebol na Terceira Idade no III Encontro Nacional de Professores de Handebol das Instituições de Ensino Superior do Brasil, em amadurecidos pelo Prof. Francisco de Assis, juntamente com seus alunos àquela época, culminando no que hoje temos como Master Handebol.

Farias ${ }^{(1)}$ descreve como o Master Handebol deve ser jogado, onde o mesmo tem como base as regras do handebol indoor, praticado em ginásio de esportes, respeitando algumas condições, gerais e específicas, da modalidade.

Considerando as condições gerais, uma das principais características do Master Handebol é o fato do jogo ser desenvolvido em áreas distintas. Existem atacantes e defensores distintos, divididos nas duas metades da quadra. Com isso, cada equipe pode ter até 9 jogadores em quadra ao mesmo momento, onde um deles é designado como goleiro, 4 jogadores como atacantes e outros 4 como defensores.

Master Handebol também pode ser desenvolvido em naipe misto, onde homens e mulheres jogam juntos. Contudo, a proporcionalidade dos jogadores de quadra, com exceção do goleiro, deve ser igual para ambos os gêneros, sendo metade do gênero feminino e outra metade do gênero masculino, sejam eles atacantes e/ou defensores.

Como condições específicas, podemos citar o fato da quadra ser dividida por uma linha central, onde é proibido ao jogador, com ou sem bola, tomar vantagem do espaço ou pisar nessa linha, tendo como consequência um tiro livre para a outra equipe. É proibido passar a bola direto do goleiro para a equipe atacante, seja através de um tiro de meta ou através de um tiro de saída, que no caso também é cobrado pelo goleiro, da mesma forma que se cobra o tiro de meta. A zona de substituição é a mesma para ambas as equipe, sendo demarcada para os dois lados, a partir da linha central, um prolongamento de 4,5m. Os gols só poderão ser marcados pelos jogadores que estão como atacantes da equipe.

\section{MATERIAL E MÉTODOS}

A fim de atingirmos com mais eficácia os objetivos em questão, realizamos um estudo descritivo e exploratório, de abordagem qualitativa, a qual possibilita maior aproximação com o cotidiano e as experiências vividas pelos próprios sujeitos.

0 trabalho foi realizado com ex-atletas que participam dos Festivais de Master Handebol, na cidade de Maceió - AL. 0 grupo estudado foi constituído de 11 sujeitos, sendo 6 do gênero feminino e 5 do gênero masculino, com idades compreendidas entre 30 e 66 anos, conforme é mostrado no Quadro 1. Os sujeitos foram identificados por letras a fim de manter sua identidade em sigilo. 


\begin{tabular}{|c|c|c|}
\hline SUJEITO & GÊNERO & IDADE \\
\hline A & $\sigma^{\prime}$ & 35 anos \\
\hline B & $\sigma^{\prime \prime}$ & 39 anos \\
\hline c & ㅇ & 31 anos \\
\hline D & ㅇ & 39 anos \\
\hline E & $\sigma^{\circ}$ & 66 anos \\
\hline $\mathrm{F}$ & $\sigma^{\prime \prime}$ & 56 anos \\
\hline G & ㅇ & 30 anos \\
\hline $\mathrm{H}$ & 우 & 49 anos \\
\hline I & 우 & 46 anos \\
\hline $\mathrm{J}$ & q & 49 anos \\
\hline K & $\sigma^{\prime \prime}$ & 50 anos \\
\hline
\end{tabular}

O processo de coleta de dados aconteceu no Ginásio de Esportes da Universidade Federal de Alagoas - UFAL, durante o IX Festival de Master Handebol, realizado no dia 15 de junho de 2013, na cidade de Maceió - AL. Utilizamos a entrevista semiestruturada, que parte de questionamentos básicos relacionados com os objetivos da pesquisa, oferecendo em seguida, amplo plano de interrogativas, à medida que surgem as respostas do sujeito. Antes de iniciarmos a coleta de dados, os sujeitos receberam esclarecimentos prévios dos objetivos do estudo, e, uma vez aceitando participar do mesmo, foram entrevistados de acordo com a disponibilidade. Isso se deu devido a pesquisa está sendo realizada paralelamente ao evento, onde o fenômeno acontece. As entrevistas foram gravadas com o uso de um gravador de voz da marca Coby (modelo CXR190-2G), e posteriormente foram transcritas, para fins de análise.

A análise dos dados teve como referencial metodológico a análise de conteúdo que procura conhecer aquilo que está por trás das palavras, sobre as quais se debruça. Trabathamos, especificamente, com a categorização que é uma operação de classificação de elementos constitutivos de um conjunto, por diferenciação e, seguidamente, por reagrupamento segundo o gênero (analogia), com os critérios previamente definidos.

\section{ANÁLISE E INTERPRETAÇÃo}

\section{DOS DADOS}

A maioria dos entrevistados já haviam participado outras vezes das edições anteriores do Festival de Master Handebol, onde somente dois, um homem e uma mulher, estavam participando pela primeira vez nesse evento.

Os resultados obtidos com as entrevistas foram analisados e discutidos de acordo com o referencial teórico, sendo agrupados nas seguintes categorias: os sentidos atribuídos à participação no Festival de Master Handebol, as representações dos sujeitos sobre o Master Handebol e os anseios relativos à periodicidade em que acontecem os festivais.

Foram usados recortes das falas dos sujeitos para apoiarem a discussão da categorias. Os recortes apresentados nesse trabalho foram identificados como os mais significativos dentre os sujeitos.

OS SENTIDOS ATRIBUÍDOS À PARTICIPAÇÃO

NO FESTIVAL DE MASTER HANDEBOL

Evidenciamos nessa categoria os motivos pelos quais os sujeitos participam dos festivais de Master Handebol. Grande parte dos sujeitos enalteceram o fato do reencontro de gerações, da rememoração do passado, do amor ao esporte e a contribuição que ele traz consigo, como podemos ver de acordo com os recortes das falas abaixo:

Ah, eu participo porque eu adoro, eu gosto muito! Aí era uma maneira, de eu, como fui atleta de handebol, permanecer jogando handebol. E o mais interessante no festival, e no Handebol Master, que é jogar com, e não contra. Então não tem adversário, você vai ver que não tem placar alí, não tem nada, é participar. Eu faço um gol alí, o camarada faz um gol lá. Então essa é a satisfação (Sujeito E). Porque, primeiramente eu amo o handebol né. Segundo porque eu tenho muitos amigos que fica difícil reencontrar daqui porque cada um trabalha, tem seus, seus [...] como é que eu posso dizer, seus compromissos fora da quadra. Então aqui é bom, o Master é bom porque a gente reencontra o pessoal, os amigos e acaba se divertindo né, fazendo o que gosta e se divertindo ao mesmo tempo (Sujeito G).

Eu participo, principalmente por isso, porque eu sempre gostei de Handebol. A minha vida foi dentro do handebol, né isso? Joguei muitos anos, fui atleta de handebol, eu viajei muito com a seleção alagoana, essas coisas. Então eu faço também por isso, porque gosto. Primeira coisa, é porque gosto! A segunda, é porque é uma coisa que a gente também pode nos encontrar, com os antigos colegas (Sujeito K).

Pode-se notar, em relação às falas dos sujeitos, que o esporte, em específico, o Master Handebol, transcende a questão da competitividade, dos valores das competições de alto nível, onde somente o que importa é a performance esportiva, confirmando à representação apresentada pelos sujeitos, onde o que é tido como primordial é a participação e a interação entre os sujeitos. 
Tendo em vista discursos como esses, consideramos de fundamental importância que, de alguma forma, os sujeitos, após a sua vida adulta, continuem praticando atividade física, e a partir disso, trazendo benefícios não só ao seu corpo, como também à sua mente, através das dimensões peculiares a tal prática. Com isso, Tubino ${ }^{(11)}$ propõe as dimensões sociais do esporte, e uma delas é o esporte-participação, onde ocorre em espaços não comprometidos com o tempo e fora das obrigações da vida diária, que, de modo geral, tem como propósitos a descontração, a diversão, o desenvolvimento pessoal e as relações entre as pessoas.

AS REPRESENTAÇÕES DOS SUJEITOS

SOBRE O MASTER HANDEBOL

Nessa categoria, enaltecemos a imagem que os sujeitos tem sobre a modalidade, sobre o que ela significa, em sua essência, para eles, o porquê deles participarem, o que os motivam a estarem juntos naquele momento. Grande parte dos sujeitos salientou um momento de relembrar o passado, à sua trajetória esportiva antes da fase pós-adulta, de acordo com os recortes abaixo:

Representa a gente voltar né, a rever os amigos, e de forma diferente a prática porque não é igual ao handebol tradicional e facilita até o desempenho, porque realmente brinca e se diverte e principalmente né, a gente mantém o nosso amor pelo handebol (Sujeito A).

É uma oportunidade de confraternização com os amigos que jogaram, que a gente iniciou há cerca de [pausa breve] 30 anos atrás [...] proporcionando um encontro pra gente um reencontro de turmas de várias gerações (Sujeito B).

Ah, é felicidade né, é o resgate, na verdade, da gente que jogou (Sujeito D).

o Master é o encontro de atletas né. É bom porque a gente reencontra o pessoal, participa do jogo, mata a saudade (Sujeito G)

Os relatos dos sujeitos trouxeram a representação não somente à prática esportiva, como também o que permeia nos bastidores do festival. Foi exaltado pelos sujeitos o que o Master Handebol representa em sua vida, sua função, seus significados, os objetivos individuais de cada sujeito ao participar em festivais.

Consideramos surpreendentes depoimentos como estes, entrando em contradição ao que vemos na sociedade, uma vez que Tubino ${ }^{(11)}$ destaca que é evidente o apelo ao esporte-performance, através dos meios de comunicação de massa que levam os gestores do esporte a esquecerem da magnitude pedagógica do esporte para a sociedade.
OS ANSEIOS RELATIVOS À PERIODICIDADE

EM QUE ACONTECEM OS FESTIVAIS

Por fim, ressaltamos os desejos individuais dos sujeitos no que se refere à frequência na qual os Festivais de Master Handebol acontecem. Todos os sujeitos, sem exceção, se demonstraram insatisfeitos com o fato dos eventos acontecerem anualmente, salientando a necessidade de haver outras edições do eventos durante o ano, reforçando sua importância para eles, conforme segue:

[...] Agora, acho que de ano em ano, se a gente tivesse outras atividades durante 0 ano, tudo bem 'taria' até bom. Mas pra gente ficar se encontrando de ano em ano, fica muito tempo. Aí nesse caso, eu acho que a gente poderia ter uma coisa assim, nos encontrar mais, [...] pra jogar, pra ir se enturmando, pra voltar outras pessoas também, começarem a voltar, para que a gente pudesse refazer o Master mesmo (Sujeito K).

Não, deveria ser assim, ter um intervalo de tempo mais curto porque o anual [pausa breve] é muito longo, a gente fica na expectativa [...] Eu 'tô' satisfeita aqui, o grupo, assim... Isso pra mim é uma alegria tá aqui sabe, eu troquei um plantão pra vim pra aqui porque eu não queria perder (Sujeito H). Era bom que tivesse mais, mais frequente, tanto pra reunir o pessoal, pra rever o pessoa, como pra divulgar mais o esporte (Sujeito $\mathrm{C}$ ).

Fica evidente, levando em consideração os apontamentos feitos pelos sujeitos, a insatisfação com o intervalo de tempo em que acontecessem os festivais, corroborando que a prática periódica, sistematizada em períodos menores aos que acontecem atualmente, seria ideal, e não apenas só uma vez ao ano.

Percebe-se que independe da idade ou gênero do sujeito, todos incorporam a atividade física às suas culturas individuais. É o que Tubino ${ }^{(11)}$ chama de homo sportivus, sujeito aquele que cada vez mais ganha relevância no mundo contemporâneo, pois além de estar presente nas diversas faixas etárias, gêneros, raças, classes sociais, apresenta-se na diversas dimensões do esporte, diferenciando-se nas suas perspectivas finalísticas e nas suas valorizações de conteúdo.

\section{CONSIDERAÇ̃̃ES FINAIS}

Mediante a análise dos sentidos presentes nas falas dos sujeitos sobre o Master Handebol, podemos considerar que em sua grande maioria, os sujeitos veem os festivais como oportunidades de rememorar o passado, o que eles trazem com os anos em meio ao esporte, aos valores adquiridos com a prática esportiva, aos preceitos recebidos através da prática pedagógica de seus professores àquela época. 
Os resultados também indicam que as representações dos sujeitos acerca dos Festivais de Master Handebol, são identificadas através do seu papel de convivência, sociabilidade entre grupos sociais distintos, no seu desenvolvimento esportivo, o que possibilita aos sujeitos exercerem a prática do esporte-participação.

Percebemos de forma notória nas falas dos sujeitos, o descontentamento em relação à periodicidade em que os Festivais de Master Handebol estão acontecendo, somente uma vez ao ano. É necessário, tendo em vista a unanimidade dos sujeitos, uma melhor sistematização da prática do Master Handebol, considerando o intervalo de tempo em que os festivais acontecem.

Nota-se também, pelos apontamentos feitos pelos sujeitos, o desejo em que o Master Handebol ultrapasse os limites alagoanos, sendo levado aos outros estados brasileiros, podendo possibilitar, a nível nacional, uma prática do handebol convencional adequada à idade e aos interesses dos seus praticantes. Grande parte desses indivíduos já praticaram o handebol e devido ao processo natural da vida, passaram da fase pós-adulta, assumindo obrigações inerentes aos seus objetivos de vida, que ocupam o espaço que antes era preenchido pela prática do handebol.

Vale ressaltar que cabe aos organizadores do evento atuarem junto às entidades que administram o esporte em âmbito nacional para, juntos, traçarem estratégias com o fim de disseminar a prática do Master Handebol. Nesse sentido, percebe-se a necessidade de maximizar a oportunidade do acesso à prática esportiva daqueles que almejam continua praticando o handebol, sendo que com objetivos diferentes da época que praticavam 0 esporte enquanto performance, nas fases jovem e adulta, onde acreditamos que possa contribuir para uma melhor qualidade de vida desta população.

Enfim, agradecemos à PROEST (Pró-Reitoria Estudantil) pelo apoio financeiro dado ao discente do Curso de Educação Física da Universidade Federal de Alagoas.

\section{REFERÊNCIAS}

1. FARIAS, F. Handebol master para ex-atletas: uma proposta de inclusão. In: GRECO, P.; ROMERO, J. (Orgs). Manual de handebol: da iniciação ao alto nível. São Paulo: Phorte, 2012.

2. FECHINE, B.; TROMPIERE, N. O processo de enveIhecimento: as principais alterações que acontecem com o idoso com o passar dos anos. Inter Science Place, América do Norte, 1, fev. 2012. Disponível em http://www.interscienceplace.org/interscienceplace/ article/view/382. Acesso em: 26 Jun. 2013.

3. GUARESCHI, P. Representaçōes sociais: alguns comentários oportunos. In: NASCIMENTO-SCHULZE, C. (org.). Novas contribuições para a teorização e pesquisa em Representação Social. Florianópolis: [s. n.] 996. Coletâneas da ANPEPP, p. 9-30.

4. MOSCOVICI, S. Representações sociais: Investigações em psicologia social. Petrópolis, Vozes, 2003. 5. MURRAY, C.; LOPEZ, A. Mortality by cause for eight regions of the world: global burden of disease study. Lancet, v. 349, n. 9061, p. 1269-1276, May 1997.

6. POWERS, S.; HOWLEY, E. Fisiologia do exercício: teoria e aplicação ao condicionamento e ao desempenho. 3. ed. São Paulo: Manole, 2000.

7. REIS, S.; BELLINI, M. Representações sociais: teoria, procedimentos metodológicos e educação ambiental. Acta Scientiarum. Human and Social Sciences. Maringá, v. 33, n. 2, p. 149-159, 2011.

8. SÁ, C. A construção do objeto de pesquisa em representações sociais. Rio de Janeiro: EdUERJ, 1998.

9. SANTIAGO, L. Corpo, tempo e valores contemporâneos. In: ALBUQUERQUE, A.; SANTIAGO, L.; FUMES, N. (Orgs.) Educação Física, Desporto e Lazer: perspectivas luso-brasileiras. Alagoas: ISMAI/EDUFAL, 2008 p. 199, 208.

10. SANTOS, M. A teoria das representações sociais. In: SANTOS, M.; ALMEIDA, L. Diálogos com a teoria das representações sociais. Ed. Universitária da UFPE, 2005. 11. TUBINO, M. Dimensões sociais do esporte. 3. ed. São Paulo: Cortez, 2011. (Coleção questões da nossa época; v. 25) 